\title{
Association of Hemoglobin Electrophoretic Phenotype with Human Parvovirus B19 infection among Pregnant Women attending Abuja Tertiary Hospital, Nigeria
}

\author{
Idris Nasir Abdullahi \\ Department of Medical Laboratory \\ Science, Ahmadu Bello University, \\ Zaria, Nigeria \\ Hafeez Aderinsayo Adekola \\ Department of Microbiology, Olabisi \\ Onabanjo University, Ago Iwoye, \\ Nigeria \\ Anthony Uchenna Emeribe \\ Department of Medical Laboratory \\ Science,University of Calabar, \\ Calabar, Nigeria \\ Abdurrahman El-fulaty Ahmad \\ Department of Medical Laboratory \\ Science, Ahmadu Bello University, \\ Zaria, Nigeria \\ Thairu Yunusa \\ Department of Medical Microbiology \\ and Parasitology, University of Abuja, \\ Nigeria \\ Bamidele Soji Oderinde \\ Department of Medical Laboratory \\ Science, University of Maiduguri, \\ Maiduguri, Nigeria \\ Dele Ohinoyi Amadu \\ Department of Medical Microbiology \\ and Parasitology, University of Ilorin \\ Teaching Hospital, Nigeria \\ Maryam Muhammad Zakari \\ Department of Obstetrics and \\ Gynecology, University of Abuja \\ Teaching Hospital, Abuja, Nigeria \\ Nkechi Onukegbe Peters \\ Department of Strategic Information, \\ Nigerian Institute of Human Virology, \\ Abuja, Nigeria \\ Sanusi Musa \\ Department of Medical Laboratory \\ Science, Ahmadu Bello University, \\ Zaria, Nigeria \\ Corresponding author: Iddris Nasir \\ Abdullahi \\ Address: Department of Medical \\ Laboratory Science, College of \\ Medical Sciences, Ahmadu Bello \\ University, Zaria, Nigeria \\ Email: eedris888@yahoo.com
}

Received: 2020/03/27

Revised: 2020/04/10

Accepted: 2020/04/12

\section{(c) (i) (8)}

This work is licensed under a Creative

Commons Attribution 4.0 License.

\begin{abstract}
Background and Objectives: Human parvovirus B19 (B19V) has singular tropism to erythropoietic cells and causes a wide range of complications in some fetuses of infected pregnant women, especially those with hemoglobinopathies. This study aimed to determine association of hemoglobin electrophoretic patterns and other risk factors of $\mathrm{B} 19 \mathrm{~V}$ in pregnant women attending University of Abuja Teaching Hospital (UATH), Abuja, Nigeria.

Methods: Blood samples were collected from 200 pregnant women and screened for antiB19V Immunoglobulin-VI (IgM), Immunoglobulin-G ( $(g G)$ and hemoglobin phenotypic pattern using enzyme immunosorbent assay and Minicap Flex Piercing Electrophoresis, respectively. Structured questionnaires were used to collate sociodemographic variables and associated risks for $\mathrm{B} 19 \mathrm{~V}$.
\end{abstract}

Results: 0f the 200 participants, 12 (6.0\%) were positive for Bl9V IgII, 45 (22.5\%) positive for IgG, 2 (1.0\%) were positive for both antibody classes while 145 (72.5\%) had no detectable B19V antibodies. Twenty-six (20.3\%) of subjects with Hemoglobin AA (HbAA) electrophoretic pattern had B19V IgC, $9(12.5 \%)$ in those with HbAS and $11(30.6 \%)$ in those with HbSS electrophoretic pattern. There was significant association between prevalence of anti-B19V IgC and hemoglobin electrophoretic pattern of participants (p value $=0.037$ ). However, no association between B19V IgII and hemoglobin electrophoretic pattern, age and parity of pregnant women (p value $>0.05$ ).

Conclusion: Findings from this study revealed a high prevalence of $\mathrm{B} 19 \mathrm{~V}$ infection. Recent B19V infection was associated with hemoglobin electrophoretic profile of pregnant women. It is recommended to follow all pregnant women with anti-B19V IgVI positive results and their fetuses.

Keywords: Anemia, B19 Viremia, Maternal infection, Sero-survey

This paper should be cited as: Abdullahi IN, Adekola HA, Emeribe AU, El-fulaty Ahmad A, Yunusa T, Oderinde BS, et al. [Association of Hemoglobin Electrophoretic Phenotype with Human Parvovirus B19 infection among Pregnant Women attending Abuja Tertiary Hospital, Nigeria]. mljgoums. 2020; 14(3): 33-39. 


\section{INTRODUCTION}

The human Parvovirus-B19 (B19V) is a naked and single stranded Deoxyribonucleic Acid (DNA) virus with negative sense polarity (1). This virus mainly infects red cells progenitor and causes vating forms of severe hematological disorders $(1,2,3)$ It belongs to the genus Erythroparvovirus of the Parvoviridae family (3). Human Parvovirus B19 has been an important pathogen responsible for several diseases such as transient aplastic crisis, non-immune hydrops fetalis in pregnant women, fifth disease in children, persistent anemia in immunocompromised patients since its discovery causing morbidity and mortality among different populace $(2,4)$. Immature cells in the erythroid lineage are principal targets for Human Parvovirus B19, hence replication of this virus causes cell death and interruption of red cell production (5).

Human Parvovirus B19 can be transmitted via the respiratory route, blood, bone marrow or organ transplantation and also through vertical transmission during pregnancy where it can cause severe fetal anemia, miscarriage, fetal death or hydrops fetalis $(6,7,8)$. Its prevalence in pregnant women has been reported to be $1-5 \%$ but could spike up to around $10.0 \%$ during epidemics. 10 Although, the reported seroprevalences in pregnant women differ between countries. For instance, $13.2 \%$ in Nigeria and $3.3 \%$ in South Africa (5, $7,9)$. B19V infection during pregnancy may result in variety of signs of fetal damage and the risk of damage increases if infection occurs in the first two trimester of the pregnancy (10, 11).Epidemiologically,child-bearing age women have been reported to undergo seroconversion rate of $1.5 \%$ (12). Even though the prevalence of anti-B $19 \mathrm{~V}$ in the general population in quite high, acute infections or presence of viral DNA is not common (12). The pathogenesis and pattern of clinical disorders caused by B19V varies and largely depend on the hematological and immune status of the infected persons (13). In individuals with normal hemoglobin, B19V infection is self-limiting and generally causes a rash or arthralgia preceded by subclinical erythroid aplasia (13). Nonetheless, in individuals with impaired erythrocytes production, B19V infection results in a severe drop of hemoglobin values, causing anemia which could be life threatening $(13,14)$.
B19V infection has been generally linked with individuals having the sickle cell disease (Hemoglobin SS electrophoretic pattern). The infection is particularly common in young children but less frequent in adults $(15,16)$. In sickle cell anemic (SCA) patients, both acute and chronic B19V infection occurs. B19V infection may precipitate prolonged SCA vaso-occlusive crisis, splenic sequestration, myocarditis and cardiac dysfunction (13).

It has been estimated that $5 \%$ to $7 \%$ of the global population carries abnormal hemoglobin phenotypes (17). Out of this, the sickle hemoglobin (HbS) carrier had reported to be $25 \%$ to $40 \%$. Globally, Nigeria bears the highest burden of sickle cell disease. Until recently, other clinically significant hemoglobin phenotypic variants were largely unavailable (17). For instance, in a recent Nigerian study, the most frequent hemoglobin phenotypes were $\mathrm{HbAA}$ (59.4\%), then $\mathrm{HbAS}$ $(23.3 \%)$ and SS (13.3\%). Hover, HbAC was detected in $2.1 \%$, $\mathrm{HbSC}$ in $0.9 \%$ and $\mathrm{HbCC}$ in $0.2 \%$ (17). The immunological status of pregnant women places them at high risk of B19 infection, the risk of vertical transmission to the fetus is one out of every two B19V infections in pregnant women, and when transmission occurs, fetal disease manifestations usually present two weeks after which lasts till eight weeks after infection (6). Hydrop fetalis is commonly due to vertical transmission of B19V (13, 15, 17). Although the $\mathrm{B} 19 \mathrm{~V}$ is not majorly teratogenic pathogen, but it can cause severe fetal mortality and morbidity. Therefore, assessment for B19V maternal infection should be carried out to determine the risk of fetal transmission and plan for appropriate medical interventions to minimize fetal B19V-associated morbidity and mortality $(10,11,18)$.

Due to their defective immune function, persons with sickle cell anaemia are believed to contract severe forms of $\mathrm{B} 19 \mathrm{~V}$ associated complications. Hence, fetuses to HbSS mothers are high risks of developing the aforementioned B19V-associated disorders or miscarriages. Indeed, there are many serological studies on B19V in Nigeria. However, no study investigated the association of hemoglobin electrophoretic profile on the seroprevalence of acute B19V infection. With this, the present study was instigated to determine association of hemoglobin electrophoretic patterns and associated risk 
factors of $\mathrm{B} 19 \mathrm{~V}$ in pregnant women attending University of Abuja Teaching Hospital, (UATH) Gwagwalada, Abuja, Nigeria.

\section{MATERIAL AND METHODS}

\section{Study Design and Area:}

This hospital-based cross-sectional study was conducted at the University of Abuja Teaching Hospital (UATH) situated at the Federal Capital Territory (FCT) of Nigeria. It is the major referral hospital that provides healthcare services to the suburbs of Abuja.

\section{Ethical Consideration}

This study was approved by the Ethical Research Committee of the UATH, Abuja. All participants gave written informed consent or accent (as the case may be) before enrollment in to the study. This study was conducted accordance with the Declaration of Helsinki of 1973 (revised in 2000).

Determination of Sample Size:

The minimum required participants for this study was determined using the following expression:

$$
\begin{aligned}
& \mathrm{n}=\frac{\mathrm{Z}^{2} \mathrm{Pq}}{\mathrm{d}^{2}} \\
& \text { Where, } \mathrm{n}=\text { Minimum sample size } \\
& \qquad \mathrm{z}=\text { the standard } \\
& \text { normal deviation usually set at } 1.96 \\
& \mathrm{p}=\text { prevalence rate } \\
& \text { from a previous study } \\
& \mathrm{q}=1-\mathrm{p} \\
& \mathrm{d}=\text { degree of accuracy set at } 0.05
\end{aligned}
$$

Using the prevalence of $4.0 \%$ of $\mathrm{B} 19 \mathrm{~V}$ infection among pregnant women some hospitals in Nigeria (11). Hence a minimum sample size of 60 was calculated. However, 200 consented pregnant women were enrolled to improve the statistical credence of the study.

\section{Sampling Technique}

Participants were selected by simple randomization. The first number is selected using random number table. This is done on every antenatal day until the required sample size is achieved.

\section{Participants' Selection Criteria}

Pregnant whom present with febrile illness regardless of the onset of the symptom and consented to participate in the study. Those who did not present with febrile illness, those with malaria, comorbidity and chronic disorders such as diabetes mellitus and Human Immunodeficiency Virus and Acquired Immunodeficiency Syndrome (HIV/AIDS) were excluded. As a principle, all pregnant women will fever are usually tested for malaria. Hence, malaria testes results were accessed from their hospital holders.

\section{Sample Collection and Preparation}

Whole blood samples of five milliliter (5 $\mathrm{mL}$ ) were collected aseptically. Three milliliters were dispensed into ethylenediaminetetraacetic acid (EDTA) containers and used for the determination of hemoglobin phenotype and the serum from remaining was harvest and used for anti-B19V serology. Analysis were conducted in batches and within 2 to 3 hours of sample collection.

\section{Laboratory Analytical Procedures}

\section{Determination of Hemoglobin Phenotype}

The hemoglobin electrophoresis of the participants' whole blood was analyzed using Minicap Flex Piercing Electrophoresis equipment (Sebia, UK) as described by equipment manual.

\section{Determination of Anti-Human Parvovirus IgM and IgG antibody}

Serum Parvovirus B19V IgM and IgG were investigated using indirect ELISA. Assays were carried out and results interpreted according to the method described by kit manufacturer (Euroimmun ®, Leubeck, Germany).

\section{Statistical analysis}

Statistical Package for Social Science (SPSS) Version 24 was used to analyzed data generated from this study. Results were presented in frequencies, percentages and mean \pm standard deviation (S.D.) (for continuous variables). Chi-square was used to determine association between two categorical variables. $P$ values $<0.05$ at confidence interval of $95 \%$ were considered statistically significant.

\section{RESULTS}

A total number of two hundred samples were collected and tested for Human Parvovirus B19 IgG and IgM antibodies from pregnant women attending University of Abuja Teaching Hospital. The Seroprevalence of anti-B19V IgG and IgM was investigated among the pregnant women. Two $(1,0 \%)$ tested positive for both $\operatorname{IgM}$ and $\operatorname{IgG}$, this indicates re-infection or seroconversion; 43 $(21.5 \%)$ 
tested $\operatorname{IgG}$ positive and $\operatorname{IgM}$ negative, this indicates past infection or seroconversion of from active infection. While $10(5.0 \%)$ were IgG negative and IgM positive, which indicated acute or recent $\mathrm{B} 19 \mathrm{~V}$ infection, the remaining $135(72.5 \%)$ were negative for both IgM and $\operatorname{IgG}$ (Table 1).

The distribution of the anti-B19V was also determined across the hemoglobin electrophoretic pattern of the participant. Ninety-two had Hemoglobin AA (HbAA) electrophoretic pattern and 72 had HbAS electrophoretic pattern, while the remaining 36 had HbSS electrophoretic pattern. Out of the 92 participants with HbAA electrophoretic pattern $7.6 \%$ were positive for anti-B19V IgM while $28.3 \%$ were positive for anti-B19V IgG. Among participants with HbAS hemoglobin electrophoretic pattern, $4.2 \%$ were positive for anti-B19V IgM while $12.5 \%$ were positive for anti-B19V IgG. Lastly, among participants with HbSS hemoglobin electrophoretic pattern, $2(5.6 \%)$ were positive for anti-B19V IgM and $30.6 \%$ were positive for anti-B19V IgG (Table 2).

Table 1 Sero-prevalence of Human Parvovirus-B19 Immunoglobulin-G and -M among Pregnant Women with their Corresponding Inferences

\begin{tabular}{lcll}
\hline Antibodies & No. of subjects $(\%)$ & Inference \\
& & \\
\hline 1. & B19V IgG (+ve) and IgM (-ve) & $43(21.5)$ & Past infection/seroconverted \\
2. B19V IgG (+ve) and IgM (+ve) & $2(1.0)$ & Re-infection/seroconversion \\
2. B19V IgG (-ve) and IgM (+ve) & $10(5.0)$ & Acute/ recent infection \\
3. B19V IgG (-ve) and IgM (-ve) & $145(72.5)$ & Susceptible \\
\hline
\end{tabular}

Key:

B19V = Parvovirus B19

$\mathrm{IgG}=$ Immunoglobulin $\mathrm{G}$

IgM= Immunoglobulin M

$+\mathrm{ve}=$ Seropositive

$-\mathrm{ve}=$ Seronegative

Table 2: Distribution of Anti-Parvovirus-B19 Immunoglobulin-G and -M across Hemoglobin Electrophoretic Profile of Pregnant Women

\begin{tabular}{lccc}
\hline $\begin{array}{l}\text { Hemoglobin Electrophoretic } \\
\text { pattern }\end{array}$ & No. Subject tested & No. IgM (+ve) $(\%)$ & No. IgG (+ve) (\%) \\
HbAA & & & $26(28.3)$ \\
HbAS & 92 & $3(7.6)$ & $9(12.5)$ \\
HbSS & 72 & $2(5.2)$ & $11(30.6)$ \\
Total & 36 & $12(6.0)$ & $45(22.5)$ \\
Chi-square & 200 & 0.864 & 6.621 \\
Df & & 2 & 2 \\
p value & & 0.6493 & 0.037 \\
& & & \\
\hline
\end{tabular}

*Significant association determined by Chi-squared test

Key:

B19V = Parvovirus B19

$\mathrm{IgG}=$ Immunoglobulin $\mathrm{G}$

IgM= Immunoglobulin M

$+\mathrm{ve}=$ Seropositive

-ve $=$ Seronegative

$\mathrm{HbSS}=$ Hemoglobin SS

HbAS = Hemoglobin AS

$\mathrm{HbAA}=$ Hemoglobin AA 
There was significant association between the prevalence of anti-B19V IgG and hemoglobin electrophoretic profile of participants ( $\mathrm{p}$ value $=0.037$ ).

The seroprevalence of anti-B19V IgM and IgG based on parity of the participants were also investigated, 32 participants were nulliparous, 82 were primiparous while 86 were multiparous. Among the nulliparous participants $28.2 \%$ (9) were positive for antiB19V IgG while $3.1 \%$ were positive for antiB19V IgM, out of the 82 Primiparous participants $23.2 \%$ (19) were positive for antiB19V IgG while $6.1 \%$ were positive for antiB19V IgM. Eighty-six (19.8\%) multiparous participants were anti-B19V IgG positive while $6(6.9 \%)$ were positive for anti-B19V IgM (Table 3).

The seroprevalence was highest among pregnant women who had only anti-B $19 \mathrm{~V}$ IgG positives $(21.5 \%)$, while the lowest prevalence was recorded among those positive for both anti-B19V IgG and IgM (1.0\%). Because most of the participant was negative for both antiB19 antibodies (72.5\%), they are thus susceptible to the B19V infection (Table 1).
The prevalence of anti-B19V IgM increased from $5.6 \%$ in $\mathrm{HbSS}$ to $7.6 \%$ in $\mathrm{HbAA}$, while that of anti-B19V IgG decreased from $30.6 \%$ in $\mathrm{HbSS}$ to $28.3 \%$ in $\mathrm{HbAS}$. In both cases, $\mathrm{HbAS}$ has the least prevalence with $4.2 \%$ and $12.5 \%$ for $\operatorname{IgM}$ and $\operatorname{IgG}$ respectively. There was significant no association between hemoglobin electrophoretic pattern of pregnant women with anti-B19V IgM (p value $=0.649$ ) (Table 2). The prevalence of the anti-B19V IgG in the pregnant women decreased with the increase in parity (from $28.2 \%$ in nulliparous women to $19.8 \%$ in multiparous women). However, the anti-B19V IgM seroprevalence increases with the increase in parity; from $3.1 \%$ among nulliparous women to $6.9 \%$ in multiparous women (Table 3).

It was observed that the pregnant women with age group 19-24 years have the highest prevalence of Human Parvovirus IgM $8.6 \%$ and the lowest prevalence was recorded among women in age group $\geq 37$ years and $\leq 18$ years both with $0.0 \%$ each. There was no association between age and seroprevalence of anti-B19V $\operatorname{IgM}(\mathrm{p}$ value $=0.613)($ Table 4$)$.

Table 3: Prevalence of Anti-Parvovirus B19 Immunoglobulin-G and -M by Parity of Pregnant Women

\begin{tabular}{|c|c|c|c|c|c|c|c|}
\hline Parity & $\begin{array}{l}\text { No. Subject } \\
\text { tested }\end{array}$ & $\begin{array}{l}\text { No. IgG (+ve) } \\
(\%)\end{array}$ & Chi-squared & $P$ value & $\begin{array}{l}\text { No. IgM } \\
(+ \text { ve) }(\%)\end{array}$ & $\begin{array}{l}\text { Chi- } \\
\text { squared }\end{array}$ & $\mathrm{p}$ value \\
\hline Nulliparity & 32 & $9(28.2)$ & 0.970 & 0.6157 & $1(3.1)$ & 0.726 & 0.6954 \\
\hline Primiparity & 82 & $19(23.2)$ & & & $5(6.1)$ & & \\
\hline Multiparity & 86 & 17 (19.8) & & & $6(6.9)$ & & \\
\hline Total & 200 & $45(22.5)$ & & & $12(6.0)$ & & \\
\hline
\end{tabular}

Key:

B19V = Parvovirus B19

IgG = Immunoglobulin $\mathrm{G}$

IgM= Immunoglobulin M

$+\mathrm{ve}=$ Seropositive

-ve $=$ Seronegative

Table 4: Seroprevalence of Anti-Parvovirus-B19 Immunoglobulin M by Age of Pregnant Women

\begin{tabular}{|c|c|c|c|c|}
\hline Variable & Observation & $\begin{array}{l}\text { No. tested } \\
(+\mathrm{ve})(\%)\end{array}$ & No. IgM & Chi-Squared \\
\hline Age, years (mean \pm S.D.) & $26.3 \pm 6.39$ & 200 & & NA \\
\hline \multirow[t]{6}{*}{ Age range (years) } & a. $\leq 18$ & 15 & $0(0.0)$ & \\
\hline & b. $19-24$ & 70 & $6(8.6)$ & \\
\hline & c. $25-30$ & 69 & $4(5.8)$ & \\
\hline & d. $31-36$ & 32 & $2(6.3)$ & \\
\hline & e. $\geq 37$ & 14 & $0(0.0)$ & \\
\hline & Total & 200 & $12(6.0)$ & 2.680 \\
\hline
\end{tabular}

$P$ value

NA

B19V = Parvovirus B19

IgM= Immunoglobulin M

$+\mathrm{ve}=$ Seropositive

-ve $=$ Seronegative

S.D. = Standard Deviation 


\section{DISCUSSION}

Parvovirus B19 is one of the most common viral infections that cause fetal infection in non-immune pregnant women (6). Although the B19 virus is not majorly teratogenic but infection can cause severe fetal mortality and morbidity (10).

About $6.0 \%$ of the pregnant women had detectable anti-B19V IgM, which indicated recent. This is similar to findings of a Libyan and an Iran studies which reported anti-B19V IgM seroprevalence of $5 \%$ and $10 \%$, respectively, among pregnant women $(19,20)$. It should be considered that $1.0 \%$ of participants had B19V re-infection. This may be due to pregnancy-associated immunocompromise or reinfection with a different B19V genotype or strain. It appears that many pregnant women, $145(72.5 \%)$ were not immune to this virus during pregnancy. This B19V IgM seroprevalence is lower than those reported by Akyala et al (20) in Northcentral Nigeria. From this current study, the prevalence of anti-B19V IgG was $22.5 \%$. This closely in conformity with the $27.5 \%$ and $20.0 \%$ anti-B19V IgG seroprevalence among pregnant women reported by Emiasegen et al (21) and Abiodun et al (11), respectively. Our finding further corroborated with other Nigerian studies which demonstrated showed relatively high B19V infections in the country. However, the anti-B19V seroprevalence from our study was significantly lower than the $61.0 \% \mathrm{~B} 19 \mathrm{~V}$ IgG seroprevalence reported in Libya (21). This high variation may be due to the differences in endemicity of B19V infection and impacts of seasonality on the transmission B19V. Based on hemoglobin electrophoretic pattern of pregnant women, 7.6\% Seroprevalence of anti-B19V IgM antibodies among participants with hemoglobin AA (HbAA) electrophoretic pattern while the lowest prevalence $4.2 \%$ was obtained among participants with HbAS hemoglobin type, Although the findings in this study disagrees with the report of Ayolabi et al (22). Seroprevalence of anti-B19V IgG was lowest among participants with $\mathrm{HbAS}$ hemoglobin type (12.5\%), while the highest seroprevalence was obtained among participants with $\mathrm{HbSS}$ hemoglobin type $(30.6 \%)$.
This corroborated with study of SmithWhitley (16), which reported a similar seroprevalence among participants with HbSS hemoglobin electrophoretic pattern. The Seroprevalence of anti-B19V IgM was higher prevalence of $6.9 \%$ among multiparous participants and the lowest from the nulliparous participants. These findings are similar to that of Elnifro et al (21), where anti-B19V IgM positive cases where high among multiparous participants. This current study did not find significant association between the seroprevalence of anti-B19V IgM and the age groups participants. Although, it was previous reported anti-B19V IgG is age dependent (23). For instance, a large B19V serosurvey done in the United States of America showed a gradual rise in $\mathrm{B} 19 \mathrm{~V}$ IgG with age, with younger children having significantly least seroprevalence of anti-B19V compared to the elderly population. This suggests a continued exposure to the B19V infection and possibly the ease of contracting infections through various routes (23). This variation could be due to differences in infection preventive measures as the time of study and study design (age range of participants). Similar findings to ours are reported in a study at Kuwait (24). About 5.6\% HbSS pregnant women were antiB19V IgM positive. However, no significant association between seroprevalence of B19V IgM and hemoglobin phenotypes of participants. This is contrary to the study Ayolabi et al (22) which reported 14.7\% seroprevalence of $\mathrm{B} 19 \mathrm{~V}$ IgM in $\mathrm{HbSS}$ patients. Perhaps, the difference could be because their study was on general sickle cell anemic population who were not pregnant. Also, findings from this study was not in consonance with that of Jensen et al (25) which reported an association of B19V IgM and negative clinical outcome during an epidemic outbreak of B19V among 3596 pregnant women in Denmark. In addition, they reported association of acute $\mathrm{B} 19 \mathrm{~V}$ with late spontaneous abortions and stillbirths (25). This may be due difference in sample size, study population and endemicity of $\mathrm{B} 19 \mathrm{~V}$ at the period of the study. In this study, B19V IgG seroprevalence was significantly associated with hemoglobin phenotype of the pregnant women. This result is in agreement with the findings of Iwalokun et al (26) which 
demonstrated significant association of B19V IgG in with hemoglobin phenotypes, of which higher B19 IgG seroprevalence was revealed in Sickle Cell Anemic (SCA) patients than non-SCA controls. In consonance to our findings are the report of Saad et al (27) from a study of SCA patients screened for B19V infection.

\section{CONCLUSION}

Findings from this study revealed a high

\section{REFERENCES}

1. Luo Y, Qiu J. Human parvovirus B19: a mechanistic overview of infection and DNA replication. Future Virol. 2015; 10(2): 155-167. doi: 10.2217/fvl.14.103.

2. Ganaie S, Qiu J. Recent Advances in Replication and Infection of Human Parvovirus. Front Cell Infect Microbiol. 2018; 8: 166. doi: 10.3389/fcimb.2018.00166.

3. Naciute M, Meiliauskaite D, Rugirnr R, Nikitenkiene R, Jancoriene L, Mauricas M, et al. Frequency and significance of parvovirus B19 infection in patients with rheumatoid arthritis. J Gen Virol. 2016; 97(12): 3302-3312.

4. Jegede A, Aminu A, Ella E. Seroprevalence of human parvovirus B19 among patients attending some hospitals in Kano metropolis, Nigeria. Afr J Clin Exper Micro. 2014; 15(1): 21-26. DOI: 10.4314/ajcem.v15i1.4.

5. Crane J, Mundle W, Boucoiran I. Parvovirus B19 Infection in Pregnancy. J Obstet Gynaecol Can. 2014; 36(12): 1107-1116. doi: 10.1016/S1701-2163(15)30390-X

6. Lamont R, Sobel J, Vaisbuch E, Kusanovic J, Mazaki-Tovi S, Kim S, et al. Parvovirus B19 Infection in Human pregnancy. BJOG. 2011; 118 (2): 175 - 186. doi: 10.1111/j.14710528.2010.02749.x.

7. Habibzadeh S, Peeri-Doghagheh H, Mohammad-Shahi J, Mobini E, Shahbazzadegan S. The prevalence of parvovirus B19 infection among pregnant women of Ardabil in 2013. Iran J Microbiol. 2016; 8 (3): 214-218.

8. Chirambo-Kalolekesha M, Kaile T, Mwaba F, Daka V, Simakando M, Kowa S. Seroprevalence of parvovirus B19 in blood donors: the risks and challenges of blood transfusion in Zambia in the era of HIV/AIDS at the Kitwe Central Hospital, blood bank. Afr Health Sci. 2018; 18(3): 496-502. doi: 10.4314/ahs.v18i3.5.

9. Mirambo M, Maliki F, Majigo M, Mushi M, Moremi N, Seni $\mathrm{J}$, et al. The magnitude and correlates of Parvovirus B19 infection among pregnant women attending antenatal clinics in Mwanza, Tanzania. BMC Pregnancy Childbirth. 2017; 17(6): 17

10. Giorgio E, De Oronzo M, Iozza I, Di Natale A, Cianci S, Garofalo G, et al. Parvovirus B19 during pregnancy: a review. J Prenat Med 2010; 4(4): 63-66.

11.Abiodun I, Opaleye O, Ojurongbe O, Fagbami A. Seroprevalence of parvovirus B19 IgG and IgM antibodies among pregnant women in Oyo State, Nigeria. J Infect Dev Ctries 2013; 7 (12): 946-950. doi: 10.3855/jidc.3157.

12. Heegaard E, Petersen B, Heilmann C, Hornsleth A. Prevalence of Parvovirus B19 and Parvovirus V9 DNA antibodies in Paired Bone Marrow and Serum Samples from Healthy Individuals. J Clin Microbiol 2002; 40(3): 933-936.

13. Slavov S, Kashima S, Pinto A, Covas D. Human Parvovirus B19: general considerations and impact on patients with sicklecell disease and thalassemia and on blood transfusions. FEMS Immunol Med Microbiol. 2011; 62(3): 247-262. doi: 10.1111/j.1574-695X.2011.00819.x.

14. Toyokawa Y, Kingetsu I, Yasuda C, Yasuda J, Yoshida K, Kurosaka D, et al. Case of pure red aplasia complicated by Evans syndrome. Mod Rheumatol. 2007; 17(4): 333-337. prevalence of $\mathrm{B} 19 \mathrm{~V}$ infection among pregnant women attending UATH, Nigeria. In addition, anti-B19V IgG was associated with hemoglobin electrophoretic patterns of pregnant women. It is recommended to follow all pregnant women with anti-B19V IgM positive results and their fetuses.

\section{CONFLICT OF INTEREST}

None

15. Win N, Lee E, Needs M, Homeida S, Stasi R. Profound sustained reticulocytopenia and anaemia in an adult patient with sickle cell disease. Transfus Med. 2014; 24: 418-420. doi: 10.1111/tme.12168.

16. Smith-Whitley K, Zhao H, Hodinka R, Kwiatkowski J, Cecil $\mathrm{R}$, Cecil T, et al. Epidemiology of Human parvovirus B19 in children with sickle cell disease. Blood. 2004; 103 (2): 422-427. DOI: 10.1182/blood-2003-01-0069.

17. Adewoyin A, Busari O, Aworanti O. Hemoglobin Phenotypes in Nigeria: Data from a National Reference Laboratory. Am J Clin Pathol . 2019; 152(1): S115- S116.

18. Keikha F, Miri-Moghaddam E, Sharifi-Mood B. Prevalence of parvovirus B19 infection in successful and unsuccessful pregnancy in Zahedan, southeast of Iran. J Med Sci. 2006; 6: 495-7.

19-Elnifro E, Nisha AK, Almabsoot M, Daeki A, Mujber N, Muscat J. Seroprevalence of parvovirus B19 among pregnant women in Tripoli, Libya. J Infect Dev Ctries 2009; 3:218- 20.

20- Akyala I, Amuta E, Azua A, Agieni A. Parvovirus B19: Evaluation of Incidence, Prevalence and Risk Factors among Pregnant Women Attending Ante-Natal Clinic in Nassarawa stae, North Central of Nigeria. Clin Med Diag 2012; 2 (5): 5459. DOI: 10.5923/j.cmd.20120205.03.

21. Emiasegen S, Nimzing L, Adoga M, Ohagenyi A, Lekan R. Parvovirus $\mathrm{B} 19$ antibodies and correlates of infection in pregnant women attending an antenatal clinic in central Nigeria. Mem Inst Oswaldo Cruz. 2011; 106(2): 227-231. DOI: 10.1590/s0074-02762011000200018

22. Ayolabi C, Onwuzo S, Ejere J, Ibemgbo S, Solanke T. Detection of parvovirus B19 IgM in patients with sickle cell disease in Lagos, Nigeria. Asian Pac J Trop Dis. 2017; 7(7): 430-432.

23. Koch WC and Adler SP. Human parvovirus infection in pregnancy. Pediatr Infect Dis J. 1989; 8:83-87.

24. Makshed M, Pacsa A, Essa S, Ahmed M, Monem R, Surkouh M. The prevalence of antibody to human parvovirus B19 in pregnant women in Kuwait. Acta Tropica. 1999; 73(3): 225-229. DOI: 10.1016/s0001-706x(99)00033-9.

25. Jensen I, Thorsen P, Jeune BR. Vestergaard: An epidemic of parvovirus B19 in a population of 3596 pregnant Woman: a study of sociodemographic and medical risk factors. BJOG 2000;107(5): 637-43. DOI: $\quad$ 10.1111/j.14710528.2000.tb13306.x.

26.Iwalokun BA, Iwalokun SO, Hodonu SO. Seroprevalence of parvovirus B19 antibodies and evidence of viremia among Nigerian patients with sickle cell anemia. J Biomed Res. 2013; 27: 272-82.

27. Saad AA, Beshlawi I, Al-Rawas AH, Zachariah M, Nazir HF, Wali Y. Human Parvovirus B19 in Children with Sickle Cell Disease; Poking the Spleen. Oman Med J. 2017; 32(5): 425-428. doi: 10.5001/omj.2017.79. 